\title{
ARMADILHAS NO LABIRINTO: A CONFORMAÇÃO POLÍTICO-PEDAGÓGICA À AGENDA EDUCACIONAL NEOLIBERAL E SEU IMPACTO NO TRABALHO DOCENTE
}

\author{
Rosivaldo Pereira de Almeida \\ Universidade Estadual de Goiás (UEG), Cidade de Goiás, Goiás, Brasil \\ SANDRA VALÉRIA LIMONTA ROSA \\ Universidade Federal de Goiás (UFG), Goiânia, Goiás, Brasil
}

\begin{abstract}
Resumo: O artigo apresenta a síntese de uma pesquisa que objetivou compreender e analisar criticamente o processo de empresariamento da educação pública no estado de Goiás. Por meio de pesquisa bibliográfica e análise documental, fundamentadas no referencial teórico-metodológico do materialismo histórico dialético, analisamos os principais programas implementados pela Secretaria Estadual de Educação, Cultura e Esportes que materializaram nas escolas estaduais o "Pacto pela Educação", um conjunto de reformas proposto por essa secretaria no ano de 2011. Os resultados da pesquisa apontam para a criação de novas formas de controle e conformação do trabalho docente a determinadas concepções políticas e pedagógicas, cuja gênese está na agenda educacional neoliberal, propagadas principalmente pelo Banco Mundial.

Palavras-chave: Agenda educacional neoliberal. Trabalho docente. Empresariamento da educação.
\end{abstract}

A IMPLEMENTAÇÃO DA AGENDA EDUCACIONAL NEOLIBERAL DO BANCO MUNDIAL COMO POLÍTICA PÚBLICA DE EDUCAÇÃO - CONSIDERAÇÕES INICIAIS

Em nosso país, na última década, tem se intensificado o que denominamos em nossa pesquisa de "processo de empresariamento da educação pública". Trata-se de um grande, complexo e muito bem organizado movimento que congrega entidades, instituições e fundações umbilicalmente ligadas a grandes empresas e bancos e que têm conseguido inserir, nas políticas educacionais, concepções, orientações e conteúdos que traduzem, sem nenhuma dúvida, a agenda educacional neoliberal propagada, principalmente, pelo Banco Mundial (BM).

Os processos de intensificação e precarização do trabalho docente vão se agudizando e podemos observar nas redes de ensino brasileiras que tais processos são marcados por características gerais, conforme Santos e Limonta (2014, p. 187-188), que muitas vezes escapam aos pesquisadores do campo das políticas educacionais:

1. Redução do tempo livre (ao terem que trabalhar em diferentes unidades de ensino, fator que aumenta suas jornadas laborais e, 
que em vários casos, são estendidas para fora do que é tolerado pela Legislação Trabalhista em vigor); 2. Aumento dos vínculos empregatícios parciais, temporários, terceirizados, comissionados, etc. (que ao serem muito cobrados em sua produtividade e sem contar com o maior amparo legal, amargam com a instabilidade e a inseguranc,a); 3. Falta de recursos técnicos, humanos e financeiros para as unidades de ensino; 4. Afastamento do trabalho, devido aos problemas crônicos de saúde (síndrome de Burnout, síndrome do pânico, estresse, problemas cardiovasculares, alcoolismo, tabagismo, cancer de pele, etc.) (GASPARINI et al, 2005; CODO E MENESES, 2006); 5 . Aumento do assédio moral, do preconceito e da violencia contra os professores; 6 . Ausência de programas públicos de formação continuada de professores (dentro e fora do espaço de trabalho), situando a responsabilidade de continuidade da formação no próprio docente; 7. Achatamento salarial decorrente do enxugamento de gastos pelo Estado; 8. Perda ou deslegitimação de direitos sociais (como alterações no plano de carreira dos servidores do magistério para atender os interesses do Estado e do capital); 9. Cobrança do aumento da produtividade e dos níveis de exigencia institucionais (traduzidos pelo termo meritocracia), tanto para os docentes temporários como para os estáveis/concursados.

Em nosso país se destaca o autodenominado movimento "Todos pela Educação", em que diversas organizações empresariais e financeiras, por meio de instituições e/ou fundações, defendem reformas estruturais nas políticas educacionais alardeando que tais reformas são necessárias para a melhoria da qualidade da educação, buscando, pelo discurso próprio do mundo dos negócios, convencer gestores, professores, estudantes e suas famílias que se trata de uma necessidade urgente e inadiável.

Conforme nossa pesquisa bibliográfica e documental revela, a qualidade da educação defendida por esse e outros movimentos se constituirá em um obediente e inquestionável alinhamento político e pedagógico à lógica empresarial e, não menos importante, a valores, sentimentos e atitudes que objetivam conformar os trabalhadores e trabalhadoras, desde a escola, ao projeto neoliberal de desenvolvimento. Neste artigo, analisamos os impactos da agenda educacional neoliberal no trabalho docente e as novas formas de controle da atividade pedagógica que têm surgido. O excerto retirado do documento "Atingindo uma educação de nível mundial no Brasil: próximos passos" (BANCO MUNDIAL, 2010), reproduzido a seguir, é revelador quanto à análise que aqui fazemos:

Em Minas Gerais, Pernambuco e no município do Rio de Janeiro, dados mostram que enquanto a norma da OCDE para cada hora de instrução usada eficazmente com atividades de aprendizagem é de 85 por cento, nenhum dos sistemas brasileiros estudados passa de 66 por cento (...) os professores brasileiros usam uma proporção substancial do tempo em sala de aula praticando atividades rotineiras como fazendo a chamada e recolhendo deveres de casa. 
ALMEIDA, R. P. DE.; ROSA, S. V. L.

Uma alta proporção de professores também não faz uso dos materiais de aprendizagem disponíveis, e de 43 a 64 por cento do tempo, os estudantes estão visivelmente desocupados (em países da OCDE, o ponto de referência para estudantes desocupados é de 6 por cento ou menos do tempo) (...) Com o apoio da equipe de educacão do Banco Mundial, esses sistemas escolares também estão usando métodos padronizados de observação em sala de aula desenvolvidos nos países da OCDE para olhar dentro da "caixapreta" da sala de aula e identificar quais são os exemplos de boas práticas de professores que podem ancorar os seus programas de desenvolvimento profissional (p. 6).

Como se vê, as orientações não são nada sutis e, quanto ao seu encaminhamento, são oferecidas parcerias para treinamentos que nada menos objetivam do que controlar totalmente o trabalho do professor. Invade-se a sala de aula, a "caixa preta", retirando o pouco que restava de autonomia e dignidade ao professor na condução da atividade de ensino. Os tais métodos padronizados de observação, certamente elaborados a partir de critérios e técnicas advindos da administração, analisam o que foi observado a partir de um viés que busca legitimar o que já se sabia: a incompetência dos professores, o que justifica plenamente a elaboração de estratégias de formação e intervenção pedagógica.

"Professores excelentes: como melhorar a aprendizagem dos estudantes na América Latina e no Caribe" (BANCO MUNDIAL, 2014), é outro documento que trazemos para nossa análise. $O$ documento descreve fartamente o péssimo desempenho dos países da América Latina e Caribe no PISA ${ }^{1}$, sem que seja apresentada nenhuma análise política, social ou cultural que ajude o leitor a compreender em que contexto se produzem tais resultados e enfatizando que há uma correlação entre o desempenho dos estudantes no exame e a elevação do Produto Interno Bruto (PIB) dos países, uma relação extraordinária produzida pelo "sociologismo economicista" do neoliberalismo: os pobres são pobres porque não estudam e não estudam porque são pobres e é por isso que o PIB dos países (pobres) não se eleva.

De acordo com o documento, a "qualidade dos professores" (sic) é o fator de maior impacto na qualidade da aprendizagem dos alunos. Para Dantas e Jesus (2018), os autores do documento sustentam empiricamente esta afirmação, a partir de pesquisas realizadas com estudantes que foram ensinados por "excelentes professores", "bons professores", "professores fracos" ou "maus professores", sem explicitar em que critérios se basearam para identificar os professores como pertencentes a um ou outro grupo, o que dificulta a compreensão do que o BM entende por professores de qualidade.

${ }^{1}$ De acordo com informações obtidas no site do Ministério da Educação (www.mec.gov.br) no dia 05 de novembro de 2019, trata-se do Programa Internacional de Avaliação de Estudantes, tradução para o português de Programme for International Student Assessment, um estudo comparativo internacional, realizado a cada três anos pela Organização para a Cooperação e Desenvolvimento Econômico (OCDE). O Pisa oferece informações sobre o desempenho dos estudantes na faixa etária dos 15 anos em língua materna, matemática e ciências naturais. O Brasil participa do Pisa desde o início da avaliação, em 2000. 
Ainda segundo os autores acima citados, é preciso percorrer o documento para inferir que "professores excelentes" são os docentes que utilizam eficientemente o tempo em sala de aula para a instrução, aqueles que ocupam o maior tempo disponível ensinando, mas o que se ensina também não é muito claro: ora afirma-se que se deve dar ênfase nos conteúdos de português e matemática, ora afirma-se que o professor precisa formar determinadas competências e habilidades nos estudantes.

O documento de 2014, assim como o de 2010, aponta os principais fatores da "baixa qualidade" dos professores da América Latina e Caribe: o fato de que são, em sua maioria, mulheres e pertencentes a um extrato socioeconômico mais baixo; os cursos de formação atraem os estudantes de nível médio com menor desempenho acadêmico, não atraindo "pessoas de alto calibre" (sic) para o magistério e que são cursos demasiadamente teóricos e pouco práticos.

\begin{abstract}
Com isso, os autores não questionam a qualidade dessa formação nem apontam a necessidade de melhorá-la. Expressam preocupação apenas com a seletividade desses cursos, responsabilizando os próprios professores - e não a formação inicial - pelo baixo nível de preparação para a docência. A solução para os problemas de formação docente, conforme os autores, seria excluir dos cursos de licenciatura candidatos com mais baixos níveis acadêmicos por meio de processos seletivos mais exigentes (DANTAS E JESUS, 2018, p. 400-401).
\end{abstract}

A análise da implementação da agenda educacional neoliberal no estado de Goiás parte da compreensão das linhas gerais dessa agenda, que acreditamos ter evidenciado até aqui, e fundamenta-se nas teorias do desenvolvimento desigual e combinado (OLIVEIRA, 1987) e na categoria acumulação flexível do capital (HARVEY, 1993). A agenda educacional neoliberal se materializa no empresariamento da educação, fenômeno que não é restrito a este estado, conforme análises já realizadas, principalmente por Freitas (2011, 2012 e 2014).

No entanto, há uma particularidade do empresariamento da educação em nosso estado que justifica sua acurada análise - o "Pacto pela Educação em Goiás" -, que no nosso entendimento é constituído pelo empresariado em estreita articulação com agentes do Estado e pelo empresariado brasileiro.

Com o estabelecimento do Pacto pelo capital foi possível construir e materializar no estado de Goiás os programas Reconhecer: Educação o Mérito é Seu (2012), O Currículo Referência da Rede Estadual de Ensino (2012) e pelo Projeto Jovem de Futuro do Instituto Unibanco (2016), que abarca a organização do trabalho pedagógico do Ensino Médio Regular da Rede Pública Estadual de Ensino. Esses programas articulados a plataformas virtuais de controle e gerenciamento do trabalho docente, como CGPIU ${ }^{2}$, $\mathrm{SIAP}^{3}$ e $\mathrm{SIGE}^{4}$, se constituem como verdadeiras armadilhas contra

\footnotetext{
${ }^{2}$ Sistema de Gestão de Projetos do Instituto Unibanco.

${ }^{3}$ Sistema Administrativo e Pedagógico.

${ }^{4}$ Sistema de Gestão Escolar.
} 
o trabalho docente, no labirinto da escolarização em Goiás. Mais do que isso, em nosso entendimento, no modo de produção capitalista o fascismo se realizou como procedimento de razão e como método, práxis, no sentido stricto do termo. Isto é, se realizou como política de eliminação, modo de pensar, decidir, agir, ser e estar no mundo. A escolarização não está alheia a esse perverso processo e nesse sentido o fascismo se constitui como o próprio labirinto constitutivo do capitalismo. Se a exploração e dominação ${ }^{5}$ de um humano pelo outro são categorias históricas, desde as origens do capitalismo, pode-se afirmar que o fascismo é o meio, através do qual se faz política, inclusive educacional.

Há muito tempo se pesquisa acerca das políticas educacionais do Estado de Goiás e do Brasil. Mesmo com todas as críticas feitas pelos pesquisadores, especialmente das universidades públicas, a classe dominante, vinculada a agentes do Estado, por meio das organizações sociais e financeiras, e organismos multilaterais praticam o chamado neoliberalismo no campo da escolarização.

Tais políticas, também chamadas de "reformas educacionais", incidem diretamente sobre o trabalho docente tanto na materialização da máxima exploração da força do trabalho, como no sentido de dominação, cuja objetividade é constituir a tecnificação do trabalho docente e a treinalidade reificada.

A tecnificação do trabalho docente e a treinalidade reificada se constituíram como conceitos na tese "Armadilhas no Labirinto", de Almeida (2018), mas utilizadas como categorias de análise, não como aparecem no pensamento de forma imediata, mas como produto da realidade desvelada pelo método dialético, só puderam ser analisadas com a implementação do "Pacto Empresarial pela Educação" no estado de Goiás.

A completa tecnificação do trabalho docente só pôde ser percebida, no movimento do real, com a materialização dos sintéticos programas e projetos implementados a partir do "Pacto". Já a treinalidade reificada é, ao mesmo tempo, resultado e resultante do processo de tecnificação. Sínteses de múltiplas determinações, a tecnificação do trabalho docente e a treinalidade reificada se alimentam mutuamente nos processos de trabalho abstrato realizado pelos professores.

\section{O PACTO EMPRESARIAL PELA EDUCAÇÃO COMO ARMADILHA: GERENCIAMENTO E CONTROLE DO TRABALHO DOCENTE}

A adjetivação do Pacto pela Educação como empresarial é legitimada pelas articulações possíveis, que se constituíram no movimento do real. De acordo com Araújo Júnior (2012) o projeto do pacto foi patrocinado pela Mitsubishi, Hyundai - CAOA, Cargill e ainda contou com o apoio da Fundação Banco Itaú Social, do Instituto Unibanco, da Fundação Jaime Câmera, dos Movimentos Brasil e Goiás Competitivo, bem como do Movimento Todos pela Educação. Esta última organização se vincula a Rede Latino-Americana de Organizações da Sociedade Civil para a Educação (REDUCA). Todas elas fazem parte do campo empresarial brasileiro, vinculado ao capital financeiro

\footnotetext{
${ }^{5}$ Por meio do binômio exploração e dominação o fascismo se faz histórico, a primeira categoria de análise resulta dos processos econômicos e produtivos e a segunda por meio das instituições sociais nas quais se realizam os processos educativos.
} 
internacional por meio do Banco Mundial e do Banco Interamericano do desenvolvimento (BID).

Em nosso entendimento, os interesses economicistas dos governos e dessas organizações empresariais que se articulam aos interesses do Banco Mundial estão diretamente relacionados à "regra básica" da liberação do crédito em dinheiro, desde que os países de capitalismo periféricos adequem suas políticas educacionais à lógica neoliberal do empreendedorismo individual (ou na lógica da formação de recursos humanos - teoria do capital humano), da competitividade e da predominância da iniciativa privada sobre a esfera pública, evidenciadas pelas parcerias público-privadas e privatizações.

Foi nesse sentido que o Estado em Goiás, por meio da SEDUC realizou a reforma educacional goiana, utilizando o rearranjo organizacional e a política do Pacto para estabelecer um novo contrato em torno da escolarização. O novo contrato envolveu as parcerias público-privadas do Estado de Goiás com a Fundação Airton Senna e o Instituto Unibanco. O rearranjo envolveu os meios de comunicação de massa, o governo de Goiás, grupos políticos de partidos variados, empresários e educadores que tinham as reformas como necessárias e urgentes para "salvar" a educação em Goiás.

Em nosso entendimento, por trás dessa conformação e rearranjo haviam dois interesses que foram evidenciados em nossa pesquisa: por um lado o interesse das organizações sociais pelo acesso aos fundos públicos destinados a escolarização; por outro, o ideal de "formação" baseado na lógica da acumulação flexível, transformando a educação escolar em mercadoria ou serviço.

No Brasil, a escolarização passou a ser apresentada não mais como direito público subjetivo, propriedade social exclusiva do Estado, ou, como defendeu Oliveira (1998), antimercadoria, salário indireto formado através da lei do antivalor, mas como serviço a ser ofertado por atores da "sociedade civil". Como exemplos, temos as organizações sociais, organizações não governamentais e projetos vinculados a fundações empresariais, especialmente aquelas ligadas ao capital financeiro, como a Fundação Bradesco, o Instituto Unibanco ou Instituto Ayrton Senna (ALMEIDA, 2018, p. 133).

Conforme Silva e Siqueira (2016), a parceria com o Instituto Ayrton Senna se constituiu através da implementação dos programas "Se Liga", de alfabetização, e "Acelera Goiás", de aceleração da "aprendizagem". Trata-se de contratos celebrados entre o Estado de Goiás e a ONG Fundação Ayrton Senna.

O Se Liga tem como proposta a alfabetização de alunos em estado de defasagem idade-série, matriculados do $3^{\circ}$ ao $5^{\circ}$ ano do ensino fundamental. $O$ Programa Acelera Goiás objetiva superar o elevado índice de distorção idade/série dos alunos da Rede. A principal estratégia para correção do fluxo constituía-se na aceleração da aprendizagem, em que os alunos multirrepetentes de $1^{\circ}$ a $3^{\circ}$ série eram alocados "acelerados" em turmas/séries compatíveis com a idade.

O relatório da Controladoria Geral do Estado - CGE mostra que só no Ensino Médio foram aplicados $\mathrm{R} \$ 6.943 .989,35$ para atender aproximadamente 23.000 alunos 
ALMEIDA, R. P. DE.; ROSA, S. V. L.

nesses programas, em parcerias público-privadas pagas com o dinheiro público. Conforme Silva e Siqueira, "ao contrário do que apresentam, esses programas oferecidos pelas empresas e fundações prestadoras de serviços educacionais e contratados pela Secretaria Estadual, são pagos com as verbas da educação pública" (2016 p. 273).

A celebração do contrato com o Instituto Unibanco se estende ao ensino médio por meio do Projeto Jovem de Futuro. Trata-se de uma tecnologia educacional de gestão escolar desenvolvida por técnicos do Instituto do Unibanco, cujo objetivo apresentado é o alcance de resultados para aprendizagem dos alunos, mediante elevação das taxas do IDEB. Conforme documento do Unibanco,

(...) o Jovem do Futuro é uma tecnologia educacional concebida para o aperfeiçoamento contínuo da gestão escolar orientada para resultados de aprendizagem. A iniciativa parte do pressuposto de que a gestão escolar desempenha papel central na organização e articulação de processos e recursos disponíveis. Representa, portanto, elemento-chave na constituição de uma escola em que todos (as) tenham seu direito de aprender garantido, reduzindo desigualdades e valorizando a diversidade (UNIBANCO, 2016, p. 13).

Após a implantação do circuito de gestão, por meio do Projeto Jovem de Futuro, toda organização do trabalho pedagógico escolar foi afetada. O grupo gestor da escola, os professores e os estudantes do Ensino Médio foram alcançados por interferências em seus trabalhos em nome da gestão eficiente e elevação do IDEB. Podese dizer que a organização e gestão do trabalho pedagógico, em última análise, são feitas pelos técnicos do Instituto Unibanco que controlam o Sistema de Gestão de Projetos do Instituto Unibanco, conhecido pelos professores da Rede como CGPIU. Em síntese, desde a implantação do Circuito de Gestão do Projeto Jovem de Futuro, é o capital financeiro que exerce o total controle sobre o trabalho docente nas escolas da rede pública estadual de ensino médio.

O controle e gerenciamento do trabalho pedagógico são realizados nas seguintes etapas: planejamento do circuito; plano de ação; execução; monitoramento da rotina, adequações e registro de atividades; Sistemática de Monitoramento e Avaliação de Resultados (SMAR) e Correção de Rota. As categorias mais comuns que aparecem no documento orientador ${ }^{6}$ do circuito e que norteiam as práticas gestoriais são liderança, metas, motivação, equidade, competência, empreendedorismo etc, que fazem parte do repertório da iniciativa privada.

Resultado da articulação entre o Instituto Unibanco e do Governo de Goiás por meio da Secretaria de Estado de Educação, Cultura e Esporte o Jovem de Futuro se materializa como parceria públicoprivada e se constitui como um dos mecanismos de controle da gestão do trabalho pedagógico que articula procedimentos técnicos, o uso de redes tecnológicas virtuais e a treinalidade como metodologia. Assim como no modelo fixo de acumulação, a

\footnotetext{
${ }^{6}$ Trata-se do documento intitulado "Projeto Jovem de Futuro. Circuito de Gestão: princípios e método. Percurso formativo de gestão escolar para resultados de aprendizagem", publicado pelo Instituto Unibanco em 2016.
} 
escolarização permanece marcada pelo controle do tempo, do espaço, das relações sociais, mas com alterações na forma de realização desse controle (ALMEIDA, 2018, p. 156).

A gestão do trabalho pedagógico escolar por meio do circuito de gestão do Instituto Unibanco, o controle dos conteúdos escolares e dos ganhos salariais dos professores e gestores se deram pelos Programas Reconhecer e Currículo Referência da Rede Pública Estadual.

O Programa Reconhecer consiste na instituição do bônus de incentivo a regência, pago em dinheiro, destinado aos professores titulares de cargo efetivo da rede estadual de ensino. Trata-se de um instrumento de motivação extrínseca para os professores e gestores que atuam na regência como vantagem pecuniária, não incorporado ao salário base. Inicialmente, o bônus só era pago aos professores em regência da sala de aula, logo foi estendido ao grupo gestor da escola.

O Programa Reconhecer destaca como elementos fundamentais para o recebimento do bônus a assiduidade, a pontualidade, o desempenho eficiente, a dedicação aos registros dos trabalhos nos diários virtuais de conteúdos (SIAP) e o compromisso dos professores e gestores com a elevação do IDEB. A implementação do Programa Reconhecer insere a educação escolar pública estadual no modelo meritocrático de reconhecimento do trabalho pedagógico, adotado por outros estados da federação como São Paulo e Minas Gerais, e se materializa em consonância com o Pilar $\mathrm{n}^{\circ} 4$ do Pacto pela Educação, que estruturou o sistema de reconhecimento e remuneração por mérito.

O Bônus de desempenho dos servidores abrange o bônus de incentivo a regência e é um prêmio em dinheiro destinado aos professores no mês de junho e dezembro, caso eles cumpram os requisitos básicos como a entrega dos planos de aula no tempo determinado e não faltar nenhum dia de trabalho no semestre letivo (GOIÁS, 2011).

O Currículo Referência é um dos mecanismos de controle e gerenciamento do trabalho docente, por meio dos processos de padronização e bimestralização dos conteúdos escolares. O Pacto pela Educação gerou uma nova matriz curricular que modificou o currículo em todas as etapas escolares, do ensino fundamental ao ensino médio. Em nosso entendimento, a padronização do currículo funciona como peça fundamental no processo de alheamento do professor em relação ao trabalho docente. Já a bimestralização trata do conjunto de competências e habilidades necessárias aos estudantes para darem sequência no ano letivo. Vinculados ao calendário escolar, os conteúdos do currículo já estão prontos no SIAP, bastando ao professor arrastá-los e vinculá-los ao dia em que a atividade foi desenvolvida.

O professor acessa a plataforma online por meio de login e senha para realização do planejamento da aula. Os conteúdos, as metodologias, as avaliações e as expectativas de aprendizagem já estão descritas no SIAP, restando ao professor adentrar ao sistema e selecionar os conteúdos e expectativas que deverão ser trabalhados na 
ALMEIDA, R. P. DE.; ROSA, S. V. L.

aula, já determinada com base no calendário escolar planejado para toda a rede. Tratase da padronização de forma generalizada dos conteúdos em todas as disciplinas e escolas da rede. A justificativa da padronização é a possibilidade de transferência dos estudantes de uma escola para outra, assim como a preparação para os exames nacionais e estaduais.

\begin{abstract}
Ao mesmo tempo, será um instrumento pedagógico para orientar, de forma clara e objetiva, aspectos que não podem se ausentar no processo ensino aprendizagem em cada disciplina, ano de escolaridade e bimestre. Assim, busca-se referenciar uma base comum essencial a todos estudantes, em consonância com as atuais necessidades de ensino identificadas não somente nas legislações vigentes, Diretrizes e Parâmetros Curriculares Nacionais, mas também nas matrizes de referências dos exames nacionais e estaduais, bem como a matriz curricular do Estado de Goiás (Caderno 5). Cabe ressaltar que o Currículo Referência contempla as atuais discussões e tendências teóricas e científicas de cada área do conhecimento e da educação, em especial nas condições e necessidades reais em que se encontram os professores nas unidades educacionais (GOIÁS, 2012, p. 11).
\end{abstract}

A forma pela qual o Currículo Referência se encontra alinhado ao Sistema de Avaliação Educacional do Estado de Goiás é por meio da Avaliação Dirigida Amostral (ADA). Ao longo do ano letivo são aplicadas oito provas obrigatórias para verificação da aprendizagem com base nas competências e habilidades prescritas no currículo. A cada início e fim de bimestre é aplicada uma avaliação. A atividade de ensinar do professor passa a ser direcionada de acordo com os erros dos estudantes na ADA. Quanto mais estudantes errarem determinada questão, mais ela deverá ser trabalhada em sala de aula. Em nossa opinião, esse processo evidencia a total instrumentalização e tecnificação do trabalho docente.

O Circuito de Gestão/Jovem de Futuro, o Programa Reconhecer e o Currículo Referência formam um conjunto de mecanismos de gestão e controle da gestão do trabalho pedagógico, dos ganhos salariais dos professores e dos conteúdos escolares. Constituiu-se um sistema bem articulado de partes conectadas de controle e intensificação do trabalho do professor, utilizando-se para tal fim, além de orientações prescritivas, o uso de softwares e plataformas virtuais (SIAP, SIGE e CGPIU).

\title{
CONSIDERAÇÕES FINAIS
}

Em nosso entendimento, não se trata apenas do destroçamento da subjetividade docente, mas de sua captura, por meio de mecanismos objetivos e subjetivos de reificação constante do trabalho docente.

Aparentemente, são programas e projetos inovadores em consonância com os processos econômico-produtivos, uma mistura de modernização, modernidade e desenvolvimento através da escolarização. Na essência, a trama revela uma concepção de escolarização enviesada pelos interesses do capital, não apenas em 


\begin{abstract}
destroçar subjetividades por meio dos processos de reificação, mas da captura da subjetividade dos sujeitos por meio de novas práticas pedagógicas, a escolarização como treinalidade reificada e o processo de tecnificação do trabalho docente (ALMEIDA, 2018, p. 173).
\end{abstract}

É nesse sentido que afirmamos que a escolarização, determinada pelo capital, se constitui, na atual fase de acumulação, como elemento necessário à reificação e à treinalidade. $O$ interesse do capital na escolarização é produzir, por meio da educação escolar, indivíduos com a subjetividade capturada, tanto de professores, como de estudantes. Ambos fazem parte dessa trama. Trata-se da (de)formação dos sujeitos para que olhem e não vejam, falem e não digam, ouçam, mas não escutem.

O capital, como relação social de produção material e espiritual, com sua capacidade orgânica de se reinventar nos processos econômicos e políticos não deixaria de fora a dimensão pedagógica, objetivando educar as pessoas para serem, estarem, sentirem e agirem no mundo de acordo com as regras que ele mesmo inventou. A educação e a cultura fazem parte desse processo.

A eleição de Jair Bolsonaro para presidente da república, um entrecruzamento de ultraliberalismo econômico e conservadorismo político e cultural é, no nosso entendimento, a mais abrangente e evidente determinação do rumo para o qual a obediência à agenda educacional neoliberal conduziu a sociedade civil brasileira. Será preciso mais do que nunca uma crítica radical, científica e vigilante dos desdobramentos de tal agenda para as políticas públicas de educação nos próximos anos.

Artigo recebido em: 17/12/2019

Aprovado para publicação em: 29/03/2020

TRAPS IN THE LABYRINTH: POLITICAL-PEDAGOGICAL CONFORMATION TO THE NEOLIBERAL EDUCATIONAL AGENDA AND ITS IMPACT ON TEACHING WORK

ABSTRACT: The article presents the synthesis of a research that aimed to understand and critically analyze the process of entrepreneurship of public education in the state of Goiás. Through bibliographical research and documentary analysis based on the theoretical-methodological framework of dialectical historical materialism, we analyzed the main programs implemented by the State Department of Education, Culture and Sports that materialized the "Pact for Education", a set of reforms proposed by this secretariat in 2011. The results of the research point to the creation of new forms of control and conformation of teaching work to certain political and pedagogical conceptions, whose genesis are in the neoliberal educational agenda propagated mainly by the World Bank.

KEYWORDS: Neoliberal educational agenda. Teaching work. Educational business entrepreneurship. 
TRAMPAS EN EL LABERINTO: CONFORMACIÓN POLÍTICO-PEDAGÓGICA A LA AGENDA EDUCATIVA NEOLIBERAL Y SU IMPACTO EN EL TRABAJO DOCENTE

RESUMEN: El artículo presenta la síntesis de una investigación que tuvo como objetivo comprender y analizar críticamente el proceso de empresariamento de la educación pública en el estado de Goiás. Mediante investigación bibliográfica y análisis documental basado en el marco teórico-metodológico del materialismo histórico dialéctico, analizamos los principales programas implementados por el Departamento de Educación, Cultura y Deportes del estado, que materializó el "Pacto por la Educación", un conjunto de reformas propuestas por esta secretaría en 2011. Los resultados de la investigación apuntan a la creación de nuevas formas de control y conformación del trabajo docente a ciertas concepciones políticas y pedagógicas cuya génesis está en la agenda educativa neoliberal propagada principalmente por el Banco Mundial.

PALABRAS CLAVE: Agenda educativa neoliberal; trabajo docente; Empresariamento de la educación.

\section{REFERÊNCIAS}

ALMEIDA, R. P. de. Armadilhas no labirinto: escolarização e trabalho docente desafiados pelo pacto da educação em Goiás. Tese (Doutorado em Educação). Faculdade de Educação, Universidade Federal de Goiás, Goiânia, 2018.

ARAÚJO JÚNIOR, J. F. de. O trabalhador da educação e a acumulação flexível do capital: um estudo do posicionamento do Sintego frente à política educacional de Goiás. Dissertação (Mestrado em Educação). Faculdade de Educação, Universidade Federal de Goiás, Goiânia, 2013.

BANCO MUNDIAL. Atingindo uma educação de nível mundial no Brasil: próximos passos. Sumário executivo. Ministério da Educação: Brasília, 2010. Disponível em: http://www.todospelaeducacao.org.br/biblioteca/1390/atingindo-uma-educacao-denivel-mundial-no-brasil-proximos-passos---sumario-executivo. Acesso em 10/10/2019.

BRUNS, B.; LUQUE, J. Professores excelentes. Como melhorar a aprendizagem dos estudantes na América Latina e no Caribe. Washington: Banco Internacional para Reconstrução e Desenvolvimento/Banco Mundial, 2014. Disponível www.worldbank.org/content/dam/Worldbank/Highlights\%20\&\%20Features/lac/LC5/Po rtuguese-excellent-teachers-report.pdf. Acesso em 14/10/2019.

DANTAS, E. de A.; JESUS, W. F. de. Professores eficientes: como garantir melhores resultados com a política do Banco Mundial de controle docente. Educação: Teoria e Prática, Rio Claro, v. 28, n. 58, p. 391-407, mai./ago. 2018.

FREITAS, L. C. de. Responsabilização, meritocracia e privatização: conseguiremos escapar ao neotecnicismo? Texto apresentado no III Seminário de Educação Brasileira promovido 
pelo CEDES no Simpósio do PNE - Diretrizes para avaliação e regulação da educação nacional, em fevereiro de 2011. Disponível em www.cedes.unicamp.br/seminario3/luiz_freitas.pdf. Acesso em 1207/2017.

FREITAS, L. C. de. Os reformadores empresariais da educação: da desmoralização do magistério à destruição do sistema público de educação. Educação \& Sociedade. Campinas-SP, v. 33, n. 119, abr./jun. 2012, p. 379-404.

FREITAS, L. C. de. Os reformadores empresariais da educação e a disputa pelo controle do processo pedagógico na escola. Educação \& Sociedade, Campinas, v. 35, n. 129, out./dez. 2014, p. 1085-1114.

GOIÁS. Portaria n. 4016/GAB-SEDUC. Disciplina o Bônus de Incentivo à Regência. 2011. Disponível em http://www.agecom.go.gov.br/PDF/2011/09/14/004.pdf. Acesso em: 19 maio 2018.

GOIÁS. Secretaria de Estado da Educação (SEDUC) Pacto pela Educação: Um futuro melhor exige mudanças. Goiânia, SEDUC, 2011. Disponível em: http://www.seduc.go.gov.br/especiais/pactopelaeducacao/contato.asp. Acesso em: 20 fev. 2016.

GOIÁS. Currículo Referência da Rede Estadual de Educação de Goiás: versão experimental. $2012 . \quad$ Disponível em: http://www.seduc.go.gov.br/imprensa/documentos/?p=Arquivos/Curr\%EDculo\%20Refe r\%EAncia. Acesso em: 14 out. 2017.

GOIÁS. Programa Reconhecer: Educação, o mérito é seu Goiânia, SEDUC, 2013. Disponível

em: http://www.seduc.go.gov.br/intranet/portal/sistemas/not/files/4241/Cartilha\%20Recon hecer\%202013.pdf. Acesso em: 10 out. 2016.

INSTITUTO UNIBANCO. Projeto Jovem de Futuro. Circuito de Gestão: princípios e método. Percurso formativo de gestão escolar para resultados de aprendizagem. São Paulo: Instituto Unibanco, 2016.

SANTOS, W. B. dos; LIMONTA, S. V. Perspectivas do Banco Mundial para a formação de professores no Brasil: análise crítica. Educação: Teoria e Prática, Rio Claro, v. 24, n. 47, p. 176-194, set./dez. 2014.

SAVIANI, D. História das ideias pedagógicas no Brasil. Campinas,SP: Autores Associados, 2007.

SILVA, S. P. da; SIQUEIRA, R. M. Reforma Educacional Goiana: O Pacto pela Educação. In: LIBÂNEO, J. C.; SUANNO, M. V. R.; ROSA, S. V. L. Didática e currículo: impactos dos 
ALMEIDA, R. P. DE.; ROSA, S. V. L.

organismos internacionais na escola e no trabalho docente. Goiânia: Espaço Acadêmico, 2016.

Rosivaldo Pereira de Almeida: Doutor em Educação pela UFG (Conceito 5 na (APES), mestre em educação pela UFG, especialista em História Cultural pela Faculdade de História da UFG, especialista em Docência Universitária pela Universo/Campus Goiânia, se licenciou em História.

Orcid: https://orcid.org/0000-0001-5064-4224

Email: rosivaldo2705@hotmail.com

Sandra Valéria Limonta Rosa: Licenciada em Pedagogia pela Universidade Federal de Mato Grosso do Sul (UFMS), mestre em Educação pela Universidade Estadual Paulista Julio de Mesquita Filho (UNESP/Marília), doutora em Educação pela Universidade Federal de Goiás (UFG), realizou estágio pós-doutoral em Educação na Pontifícia Universidade Católica de Goiás (PUC GO). Professora associada da Universidade Federal de Goiás (UFG) na Faculdade de Educação.

Orcid: https://orcid.org/0000-0002-9143-4802

E-mail:sandralimonta@gmail.com

Este periódico utiliza a licença Creative Commons Attribution 3.0, para periódicos de acesso aberto (Open Archives Iniciative - OAI). 